\title{
What should we in Sri Lanka do about Zika in pregnancy
}

\author{
Pathiraja RPa ${ }^{a}$, Gunesekera DP $^{b}$ \\ Key words: Zika, pregnancy. microcephaly, fetal abnormalities
}

\section{INTRODUCTION}

Zika virus has caused concern in South American countries. Although, a mild selflimiting disease, a possible association with Guillain-Barre syndrome (GBS) ${ }^{1}$ as well as long term adverse neurological sequelae have been reported in Zika virus infected patients ${ }^{1}$. Infection in pregnant females has been causally associated with microcephaly and other severe brain abnormalities of the fetus ${ }^{2}$. Zika is an RNA flavivirus, which shares the same vector (the common mosquito Aedes aegypti), with Dengue, Chikungunya and Yellow fever viruses, prevalent in the tropics including Sri Lanka ${ }^{3}$. The recent epidemic of Zika in Bangladesh is proof of the serious threat of a Zika epidemic in Sri Lanka ${ }^{3}$.

As new facts and evidence keep emerging, the WHO has developed an ongoing systematic review to generate real time evidence-based information to collate new knowledge and identify research gaps $^{4}$. The WHO has also declared the recent clusters of microcephaly and other neurological disorders in Brazil a Public Health Emergency of International Concern $^{5}$. Therefore there is an urgent need for appropriate action by policy makers and health care providers to anticipate and prevent a possible Zika epidemic in Sri Lanka. This article aims to highlight the possible sequelae and proposed action to be taken to prevent and mitigate the effects of an epidemic of congenital Zika infection in Sri Lanka.

a Senior lecturer, Department of Obstetrics \& Gynaecology, Faculty of Medical Sciences, University of Sri Jayewardenepura, Nugegoda, Sri Lanka

${ }^{b}$ Professor and chair, Department of Paediatrics, Faculty of Medical Sciences, University of Sri Jayewardenepura, Nugegoda, Sri Lanka.

Correspondence: Dr. R. P. Pathiraja MBBS MS FRCOG FSLOG

Email-ramya_pathiraja@sjp.ac.lk

Competing interests: The authors report no conflict of interest
Reproductive age women are more likely to get infected through mosquito bites but are also at risk of infection through infected sperm of a sexual partner ${ }^{6}$. They could then potentially pass the virus vertically to the fetus when they become pregnant ${ }^{7-9}$. The viraemia lasts approximately one week in patients with a clinical infection $^{10,11}$ and there is no evidence to suggest that a fetus is at risk if conception occurred after the maternal viraemia has resolved $^{12}$. Although maternal infection with Zika virus may go unnoticed sometimes, vertical transmission could occur throughout pregnancy and lead to microcephaly and significant adverse neurological effects such as cerebral calcification, lissencephally, atrophy of white matter and frontal lobes and corpus callosum defects of the fetus and the infant ${ }^{2,7,13-15}$. Infected fetuses can present with a wide spectrum of disease, ranging from no adverse effects to microcephaly and severe impairment of brain growth, eye defects and even intrauterine fetal death ${ }^{2}$. Although microcephaly is the wellrecognized complication of congenital Zika infection, neurological abnormalities have been identified in some infants without microcephaly ${ }^{15}$. Viral RNA has also been detected after miscarriages in infected women ${ }^{16}$. Zika virus RNA has been detected in some breast-feeding mothers but so far there is no evidence of transmission through breast milk to the infant ${ }^{17}$.

\section{SITUATIONAL ANALYSIS}

As Zika is clinically indistinguishable from many other flavivirus infections, and virus excretion is limited to early infection, establishing the diagnosis is difficult. A definitive diagnosis requires detection of the virus using reverse transcription polymerase chain reaction (RT-PCR) in maternal serum, saliva or amniotic fluid, within five days of onset of symptoms. The sensitivity and specificity of RTPCR for detecting congenital infection is currently uncertain ${ }^{18}$. Viral shedding also occurs in urine up to three weeks after the onset of symptoms ${ }^{4}$. Zika specific IGM has been detected in cerebrospinal fluid by enzyme-linked immunosorbent assay, the new specific test for Zika virus ${ }^{11}$.

Routine ultrasound screening (USS) is needed for early detection of microcephaly and other abnormalities of affected fetuses. Although this is done in many obstetric units in the country, often a medical officer with limited experience will be carry out the routine USS and limited time would be spent on a patient due to the heavy workload.

Infants with congenital Zika infection will need long term follow up, especially with respect to developmental assessment and rehabilitation. Since neurological problems could occur even in infants with normal skull circumferences, it may be necessary to perform serial neuroimaging in all infants of mothers with suspected antenatal Zika infection. At present CT and MRI scanning are only available in a limited number of hospitals in Sri Lanka. Infected mothers and their families will need intensive and long-term counseling and support, especially if the infant is neurologically affected.

\section{PROPOSED INTERVENTIONS}

In order to combat a potential Zika epidemic and its adverse effects on maternal and child health, appropriate strengthening of the health care system in Sri Lanka, is imperative. Family planning and antenatal clinics, as well as social services need to be strengthened and expanded to respond to increased demand for information, counseling and sexual and reproductive health commodities ${ }^{5}$.

\section{GOVERNANCE \& LEADERSHIP}

Political commitment is essential and leadership should be given at the highest level. A multi sectoral approach with close liaison between health, education and social services and information ministries needs to be established. Even though a national level task force similar to the Dengue Task Force would be advantageous for more effective 
inter sectoral co-operation it may not be possible at present due to the lack of resources. The WHO strategic framework could be a useful tool for local adaptation ${ }^{19}$. Existing special educational facilities should be strengthened to accommodate the potential cohort of affected children. Social services should have a system of financial and social support for affected families. The ministry of information should disseminate relevant information.

\section{SERVICE DELIVERY}

At present as RT-PCR testing is available only, at $\mathrm{MRI}^{20}$ diagnostic testing needs to be prioritized for asymptomatic pregnant women with possible exposure. IgM antibody capture enzyme-linked immunosorbent assay to establish past infections would be an added benefit if available. Facilities already made available by the Ministry of Health, for rapid case detection and monitoring for effects such as fetal wastage, microcephaly and GBS in the community may need further strengthening. Case definitions for Zika virus, microcephaly, GBS and other neurological syndromes are essential. Since neurological problems are not limited to microcephalic infants, there should be a careful community surveillance of the incidence of neuro disabilities in young infants.

Guidelines on risk assessment and management of women suspected/ confirmed with Zika virus infection, and protocols for diagnosis and management of microcephaly are already in place. Validated reference charts of ultrasound fetal biometry for Sri Lanka need to be developed as the commonly used charts developed in the UK may lead to false interpretations. For detection of microcephaly and the other stigmata of congenital Zika infection, suitably trained sonologists will be needed to carry out all routine USS in pregnant women.

According to the current penal code, therapeutic abortion is possible only in life threatening conditions of the mother. Thus, pregnant women with Zika affected fetuses would have to continue with the pregnancy knowing that the baby could be severely affected. This would cause a severe psychological stress to the mother. Since termination of pregnancy is not an option, there should be a strong referral system (with repeated USS and expert counseling services), to follow up women carrying affected fetuses. In Sri Lanka, counseling services are suboptimal at present and are not a priority at the point of service delivery, and therefore needs to be strengthened.

Neuro imaging (CT/ MRI scanning) and regular follow up will be needed for all infants with presumed congenital infection. Therefore, such facilities should be available at least at provincial level.

Infrastructure for rehabilitation such as buildings, appliances and other equipment should be made available at referral centers. Facilities for educating the child with special needs should be expanded.

To detect infants with a spectrum of neurological handicap, relevant health care workers need to be trained in early detection of developmental delay and neurological assessment. Affected children will have a range of requirements, from intensive rehabilitation to special educational needs and behavioral therapy. Therefore, present facilities in these areas (including human resources) may need expansion. The cadre for specialized counselors and counseling services may need expansion. Since infection can occur in any part of Sri Lanka, it is essential to have equity of distribution of trained staff and facilities in all provinces.

\section{SOCIAL AND BEHAVIORAL CHANGE COMMUNICATIONS}

Since Zika virus can spread rapidly within the community, public awareness should be heightened. Health education materials e.g. fact sheet, posters have already been developed ${ }^{20}$, and these should be disseminated to target groups and community in general. Pregnant women should be counseled by the family health worker to present early for assessment and treatment if they develop symptoms of infection ${ }^{21}$. Since termination is not an option, infected pregnant women must receive intensive counseling and psychological support throughout their pregnancy.

\section{PREVENTION OF TRANSMISSION}

Vector control and surveillance, an integral part of controlling Zika infection, needs to be strengthened ${ }^{10}$. All patients with Zika virus infection and their sexual partners should receive information about the potential risks of sexual transmission, contraceptive measures and advice on safer sexual practices. Women who have had unprotected coitus and are concerned about possible infection should have ready access to emergency contraceptive services and counseling services ${ }^{6}$. Currently emergency contraception is not provided though the public sector. This must be corrected. Persons returning from Zika endemic areas should receive information and advice on safer sexual practices and be provided with appropriate contraceptive measures; this is already implemented with a help desk at Bandaranaike International Airport.

Currently there is no specific antiviral therapy against $\mathrm{Zika}^{21}$. Women infected with Zika should wait at least eight weeks and men should wait at least six months after onset of symptoms to attempt conception. Those with possible exposure to Zika virus but without clinical symptoms should wait at least eight weeks after exposure to attempt conception ${ }^{8}$.

In the light of current evidence, infected mothers should continue breast feeding ${ }^{17}$ . However careful surveillance is needed for possible long-term effects on the infant.

\section{GENERAL MEASURES}

The development of a vaccine against Zika infection is still in the preliminary stages with animal studies being planned at present ${ }^{22}$. As surveillance system has already been established by Family Health Bureau for microcephaly ${ }^{20}$, a system should be developed to collect data on the number of suspected cases, number tested and identified positives.

Since little is known of long-term sequelae of congenital Zika infection, promoting further research is essential. For the proposed interventions, additional financing from domestic resources will be necessary to enhance the capacity of laboratory, imaging and counseling services and infrastructure development. Indicators should also be developed to assess the impact of interventions.

All these interventions will lead to improved care in maternal and child health.

\section{CONCLUSIONS}

As Zika virus infection is spreading explosively in the tropics, Sri Lanka is at 
risk of a major epidemic. Such an event would have major deleterious effects for our women and children causing a heavy burden to the health sector and society in general. The lack of evidence based data further compounds the problem.

Although not declared a major threat to the country at present, the disastrous consequences in Brazil and other South American countries should act as a warning for us. It is hoped that policy makers and medical professionals will heed this call to action and plan ahead to mitigate the potentially serious sequelae of congenital Zika infections.

\section{REFERENCES}

1. Sonja AR, Denise JJ, Margaret AH, Lyle RP. Zika Virus and Birth Defects - Reviewing the Evidence for Causality. N Engl J Med 2016; 374:1981-1987.

2. Zika virus, microcephaly and Guillain-Barre syndrome, World Health Organization situation report, 7 April 2016.

3. Zika virus outbreak will worsen before it gets better; www. dailymail.co.uk/health.html Feb 24, 2016 (accessed on May 25 2016)

4. $\mathrm{WHO} /$ Zika virus fact sheet available at http://www.who.int/mediacentre/ factsheets/zika/en/ Apr 15, 2016 (accessed on May 24 2016)

5. WHO; Zika, strategic response framework \& joint operations plan. January-June $2016 \quad$ www. who.int/iris/handle/10665/204420 accessed 24 May 2016

6. Prevention of potential sexual transmission of Zika virus, Interim guidance 18 February 2016 WHO.
7. Oliveira MA, Malinger G, Ximenes R, Szejnfeld PO, AlvesSampaio S, Bispo DF. Zika virus intrauterine infection causes fetal brain abnormality and microcephaly: tip of the iceberg? Ultras Obst \& Gyn 2016; 47 (1): 6-7

8. Emily EP, Kara ND, Dana MD, et al. Update: Interim Guidance for Health Care Providers Caring for Women of Reproductive Age with Possible Zika Virus Exposure United States, 2016. CDC MMWR weekly report April 1, 2016; 65 (12): 315-322

9. Besnard M, Lastere S, Teissier A, CaoLormeau V, Musso D. Evidence of perinatal transmission of Zika virus, French Polynesia, December 2013 and February 2014. Euro Surveill 2014; 19 :13-6.CrossRef PubMed.

10. Hayes EB. Zika virus outside Africa. Emerg Infect Dis 2009; 15:1347-50 CrossRef PubMed

11. Lanciotti RS, Kosoy OL, Laven JJ, et al. Genetic and serologic properties of Zika virus associated with an epidemic, Yap State, Micronesia, 2007. Emerg Infect Dis 2008; 14:1232-9. CrossRef PubMed.

12. CDC Atlanta, "Zika virus". Available at. http://www.cdc.gov/zika/ providers/clinicalevaluation.html

13. Schuler FL, Ribeiro EM, Feitosa IM, et al. Possible Association Between Zika Virus Infection and Microcephaly - Brazil, 2015. $M M W R$ 2016; 65(3): 59-62.

14. WHO statement on the first meeting of the International Health Regulations (IHR 2005) Emergency Committee on Zika virus and observed increase in neurological disorders and neonatal malformations: 1 Feb 2016. Available at: http://www.who.int (accessed May 24 2016)
15. Clinical features and neuroimaging (CT and MRI) findings in presumed Zika virus related congenital infection and microcephaly: retrospective case series study) BMJ 2016; 353:11901 (accessed May 25 2016)

16. Martines RB, Bhatnagar J, Keating MK, Silva-Flannery L, Muehlenbachs A, Gary J, et al. Notes from the Field: Evidence of Zika Virus Infection in Brain and Placental Tissues from Two Congenitally Infected Newborns and Two Fetal Losses - Brazil, 2015. MMWR Morb Mortal Weekly Rep 2016; 65(6): 159-60.

17. WHO; Breastfeeding in the context of Zika virus; WHO Interim guidance 25 February2016 www. who.int/csr/resources/publications/ zika/breastfeeding/en/WHO/ZIKV/ MOC/16.5 (accessed on 27 May 2016).

18. Lyle RP, Denise JJ, Ann MP, Margaret AH. Zika Virus Review Article, $N$ Engl J Med 2016; 374:1552-1563

19. Zika Outbreak: WHO's Global Emergency Response Plan Available at www.who.int/emergencies/zikavirus/response/en/

20. http://www.epid.gov.lk/web/images/ pdf/Zika/zika_virus.pdf (Accessed 25 May 2016)

21. Zika reports; Update: Interim Guidance for Health Care Providers Caring for Women of Reproductive Age with Possible Zika Virus Exposure - United States, 2016 MMWR http://www.cdc.gov/mmwr/ volumes $/ 65 / \mathrm{wr} / \mathrm{mm} 6512 \mathrm{e} 2 \mathrm{htm}$. (Accessed on May 202016

22. http://www.geovax.com/newsevents/entry/2016/04/18/geovaxprovides-update-on-zika-vaccineprogram.html (accessed on May 25, 2016) 